Journal of Mathematics and Statistics 4 (1): 41-45, 2008

ISSN 1549-3644

(C) 2008 Science Publications

\title{
Numerical Study of Tsunami Waves with Sloping Bottom and Nonlinear Friction
}

\author{
Agustinus Ribal \\ Department of Mathematics, Faculty of Science, Hasanuddin University, \\ Makassar, Indonesia, 90245
}

\begin{abstract}
In this paper we investigate the breaking of long-waves propagating on shallow water with nonlinear friction on the sloping bottom. A complete set of equations is presented and a numerical method is developed to simulate the wave propagation. The method uses an up-wind difference scheme for the nonlinear convective term and the central difference scheme for other derivative terms. Various numerical examples have been conducted to investigate the effect of nonlinear friction and drag coefficient on wave propagation and breaking. By analyzing the numerical results, we find that in order to overcome wave breaking, nonlinear friction needs to be below certain level.
\end{abstract}

Keywords: Partial differential equations, finite difference method, wave breaking.

\section{INTRODUCTION}

Tsunami waves are defined as long-period waves created by large scale short-term perturbations such as underwater earthquakes like the 2004 Indonesian earthquake ${ }^{[21]}$, the 1969 Portuguese Tsunami ${ }^{[4]}$, and the 1968 Tokachi-oki Earthquake ${ }^{[6]}$, eruption of underwater volcanoes, for example, the 1883 Krakatau Volcano eruption ${ }^{[21]}$, landslides, for instance, the 1929 the Grand Banks landslide ${ }^{[3]}$, rock falls, pyroclastic avalanche from land volcanoes entering the water, asteroid impact, underwater explosion, etc.

The duration of a typical tsunami is $5-100 \mathrm{~min}$, with wave length between $100 \mathrm{~m}$ and $1000 \mathrm{~km}$, and propagation speed $1-200 \mathrm{~m} / \mathrm{s}$. Tsunami wave heights can be up to tens of meters ${ }^{[21]}$. The popular models to describe the tsunami wave propagation are based on the various approximations of a shallow water system. The shallow water theory in Cartesian coordinates, when no rotation is applied, is used to simulate long wave propagation. The governing equations are as follows [21].

$\frac{\partial M}{\partial t}+\frac{\partial}{\partial x}\left(\frac{M^{2}}{D}\right)+\frac{\partial}{\partial y}\left(\frac{M N}{D}\right)+g D \frac{\partial \eta}{\partial x}+\frac{k}{2 D^{2}} M \sqrt{M^{2}+N^{2}}=0$

$$
\begin{aligned}
& \frac{\partial N}{\partial t}+\frac{\partial}{\partial x}\left(\frac{M N}{D}\right)+\frac{\partial}{\partial y}\left(\frac{N^{2}}{D}\right)+g D \frac{\partial \eta}{\partial y}+\frac{k}{2 D^{2}} N \sqrt{M^{2}+N^{2}}=0 \\
& \frac{\partial \eta}{\partial t}+\frac{\partial M}{\partial x}+\frac{\partial N}{\partial y}=0
\end{aligned}
$$

where $D=h(x, y)+\eta$ is the total water depth, $\eta$ is the water surface elevation, $t$ is time, $x$ and $y$ are the horizontal coordinates in the zonal and meridional directions, $M$ and $N$ are the discharge fluxes in the horizontal plane along the $x$ and $y$ coordinates, $h(x, y)$ is the undisturbed water level, $g$ is the gravitational acceleration, and $k$ is the drag coefficient. In this paper we will investigate the breaking of long-waves propagating on shallow water with nonlinear friction on the sloping bottom.

\section{GOVERNING EQUATIONS}

In the area which is far from the source of tsunamis, the variable depth as well as nonlinear friction will influence the wave evolution [21]. For the case where the undisturbed water depth is a linear function of the horizontal $x$ coordinate as shown in Figure 1. 
Am. J. Applied Sci., 4 (1): 41-45, 2008

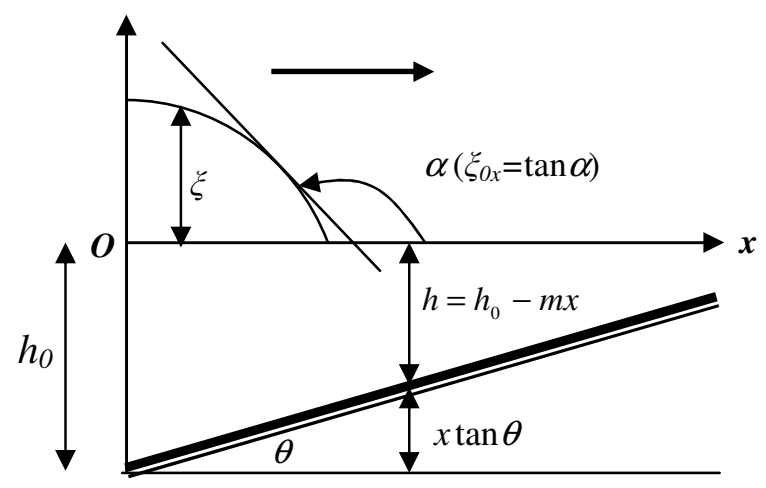

Fig. 1: Wave Profile and Coordinate System

The governing equations in section 1 can be reduced as given below.

$$
\begin{aligned}
& \frac{\partial u}{\partial t}+u \frac{\partial u}{\partial x}+g \frac{\partial \eta}{\partial x}=-\frac{k}{2 h(x)} u|u|, \\
& \frac{\partial \eta}{\partial t}+\frac{\partial}{\partial x}[(h(x)+\eta) u]=0,
\end{aligned}
$$

which are subject to the following initial conditions

$$
\eta(x, 0)=\eta_{\text {in }}(x), \quad u(x, 0)=0 .
$$

where all of the variables are as defined in section 1 .

\section{NUMERICAL SCHEME}

For the case considered, the governing equations (4) and (5) can be written as follows:

$$
\begin{aligned}
& \frac{\partial u}{\partial t}+u \frac{\partial u}{\partial x}+g \frac{\partial \eta}{\partial x}+\frac{k}{2 h(x)} u|u|=0 \\
& \frac{\partial \eta}{\partial t}+\frac{\partial}{\partial x}[(h(x)+\eta) u]=0 .
\end{aligned}
$$

For the following time derivatives, we use the forward difference scheme,

$$
\begin{aligned}
\frac{\partial u}{\partial t} & \approx \frac{u_{i, j+1}-u_{i, j}}{\Delta t}, \\
\frac{\partial \eta}{\partial t} & \approx \frac{\eta_{i, j+1}-\eta_{i, j}}{\Delta t} .
\end{aligned}
$$

For the following spatial derivatives, we use the central difference scheme,

$$
\frac{\partial u}{\partial x} \approx \frac{u_{i+1}-u_{i-1}}{2 \Delta x},
$$

$$
\begin{aligned}
\frac{\partial}{\partial x}[(h+\eta) u] & \approx \frac{\left(h_{i+1}+\eta_{i+1}\right) u_{i+1}-\left(h_{i-1}+\eta_{i-1}\right) u_{i-1}}{2 \Delta x} \\
\frac{\partial}{\partial x}(\eta) & \approx \frac{\eta_{i+1}-\eta_{i-1}}{2 \Delta x}
\end{aligned}
$$

Thus by substituting (9e) and (9d) into (8), we get,

$$
\eta_{i}^{1}=\eta_{i}-\Delta t\left\{\frac{\left(h_{i+1}+\eta_{i+1}\right) u_{i+1}-\left(h_{i-1}+\eta_{i-1}\right) u_{i-1}}{2 \Delta x}\right\}
$$

For the nonlinear convective term $u \frac{\partial u}{\partial x}$, we use the upwind difference scheme. By using Taylor's theorem, the forward and backward difference formulae can be obtained respectively as follows:

$$
\begin{aligned}
& \frac{d u}{d x} \approx \frac{u_{i+1}-u_{i}}{\Delta x}=u^{+}, \\
& \frac{d u}{d x} \approx \frac{u_{i}-u_{i-1}}{\Delta x}=u^{-} .
\end{aligned}
$$

The upwind difference scheme is defined by:

$$
u \frac{\partial u}{\partial x}=u u^{*}
$$

where

$$
u^{*}=\left\{\begin{array}{lll}
u^{-} & \text {; if } & u>0 \\
u^{+} & \text {; if } & u<0
\end{array}\right.
$$

where $u^{+}$and $u^{-}$are defined by $(9 \mathrm{~g})$ and $(9 \mathrm{~h})$.

For convenience in presentation, we introduce the sign function as below

$$
\operatorname{sgn}(u)=\frac{|u|}{u} .
$$

Thus,

$$
\begin{gathered}
u_{i}^{1}=u_{i}-\Delta t\left\{\frac { 1 } { 2 \Delta x } \left\{\left(u_{i}-\left|u_{i}\right|\right)\left(u_{i+1}-u_{i}\right)+\left(u_{i}+\left|u_{i}\right|\right)\right.\right. \\
\left.\left.\left(u_{i}-u_{i-1}\right)+g\left(\eta_{i+1}-\eta_{i-1}\right)\right\} \frac{k u_{i}\left|u_{i}\right|}{2 h_{i}}\right\} .
\end{gathered}
$$

Therefore, the finite difference scheme can be written as follows:

$$
\begin{gathered}
u_{i}^{1}=u_{i}-\Delta t\left\{\frac { 1 } { 2 \Delta x } \left\{\left(u_{i}-\left|u_{i}\right|\right)\left(u_{i+1}-u_{i}\right)+\left(u_{i}+\left|u_{i}\right|\right)\right.\right. \\
\left.\left.\left(u_{i}-u_{i-1}\right)+g\left(\eta_{i+1}-\eta_{i-1}\right)\right\} \frac{k u_{i}\left|u_{i}\right|}{2 h_{i}}\right\} \cdot \quad
\end{gathered}
$$


$\eta_{i}^{1}=\eta_{i}-\Delta t\left\{\frac{\left(h_{i+1}+\eta_{i+1}\right) u_{i+1}-\left(h_{i-1}+\eta_{i-1}\right) u_{i-1}}{2 \Delta x}\right\}$

where $\eta$ is the water surface elevation and all $u=u(x, t)$ is the horizontal component of water velocity, $h$ representing undisturbed water depth, $g$ denotes the gravitational acceleration, $k$ is the drag coefficient, $x$ and $t$ are respectively horizontal coordinate and time.

\section{NUMERICAL RESULTS}

Letting $h_{0}=10$ meters, we have $h(x)=10-m x$ where $m=\tan \theta$ and the initial water level disturbance is chosen as [20]:

$$
\xi(x, 0)= \begin{cases}\exp \left(-\frac{x^{2}}{50^{2}-x^{2}}\right) & ; 0<|x|<50 \\ 0 & ;|x| \geq 50\end{cases}
$$

The numerical results are shown in figures $2-7$. The vertical axis and the horizontal axis represent wave height $(\mathrm{cm})$ and distance from the centre of the initial wave $(\mathrm{m})$, respectively.

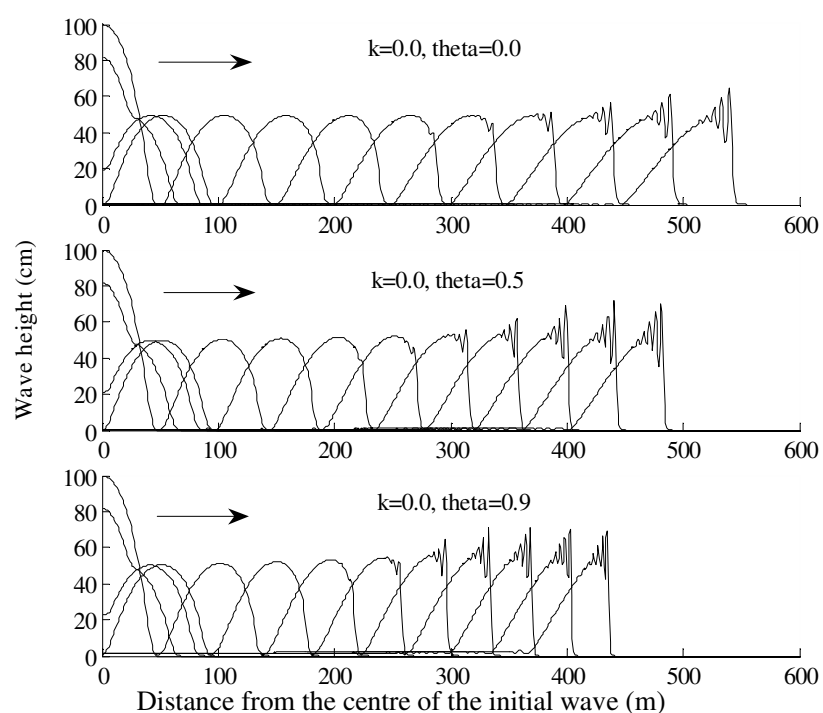

Fig. 2. Numerical results of evolution of long-waves for $k=0.0$ with different $\theta$.

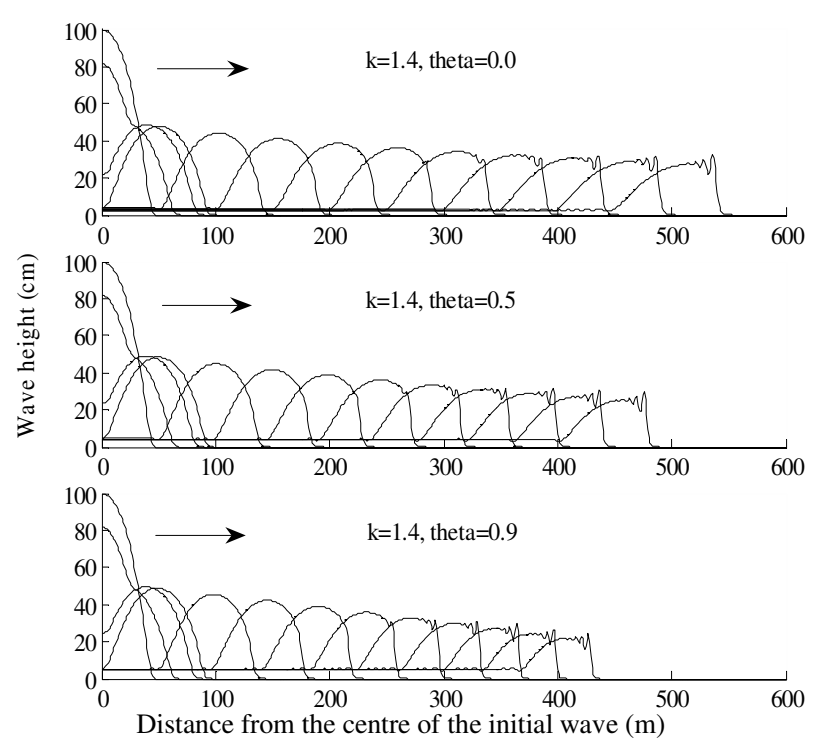

Fig. 3. Numerical results of evolution of long-waves for $k=1.4$ with different $\theta$.
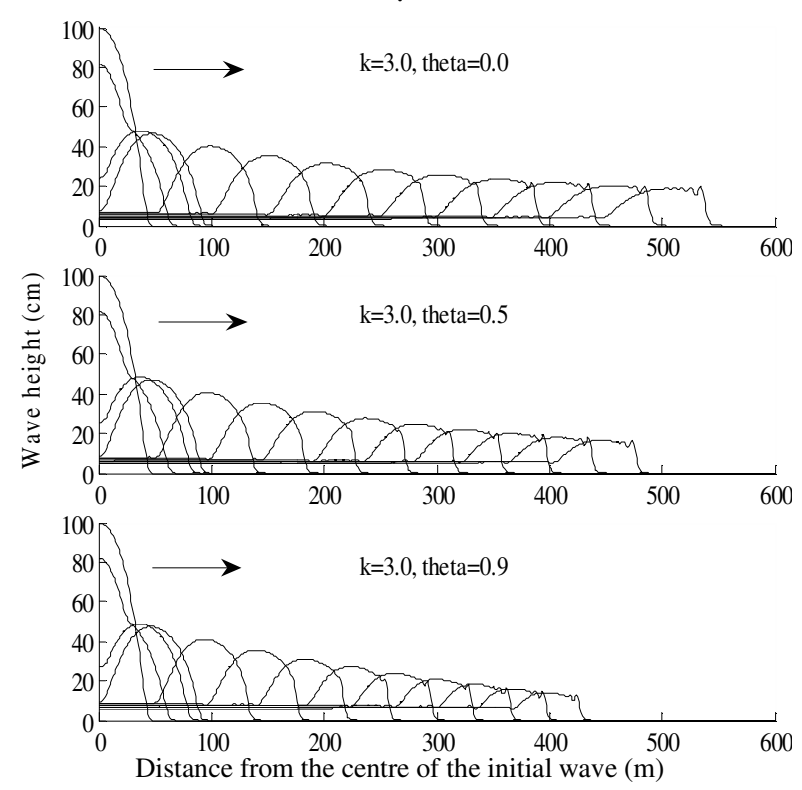

Fig. 4. Numerical results of evolution of long-waves for $k=3.0$ with different $\theta$. 
Am. J. Applied Sci., 4 (1): 41-45, 2008
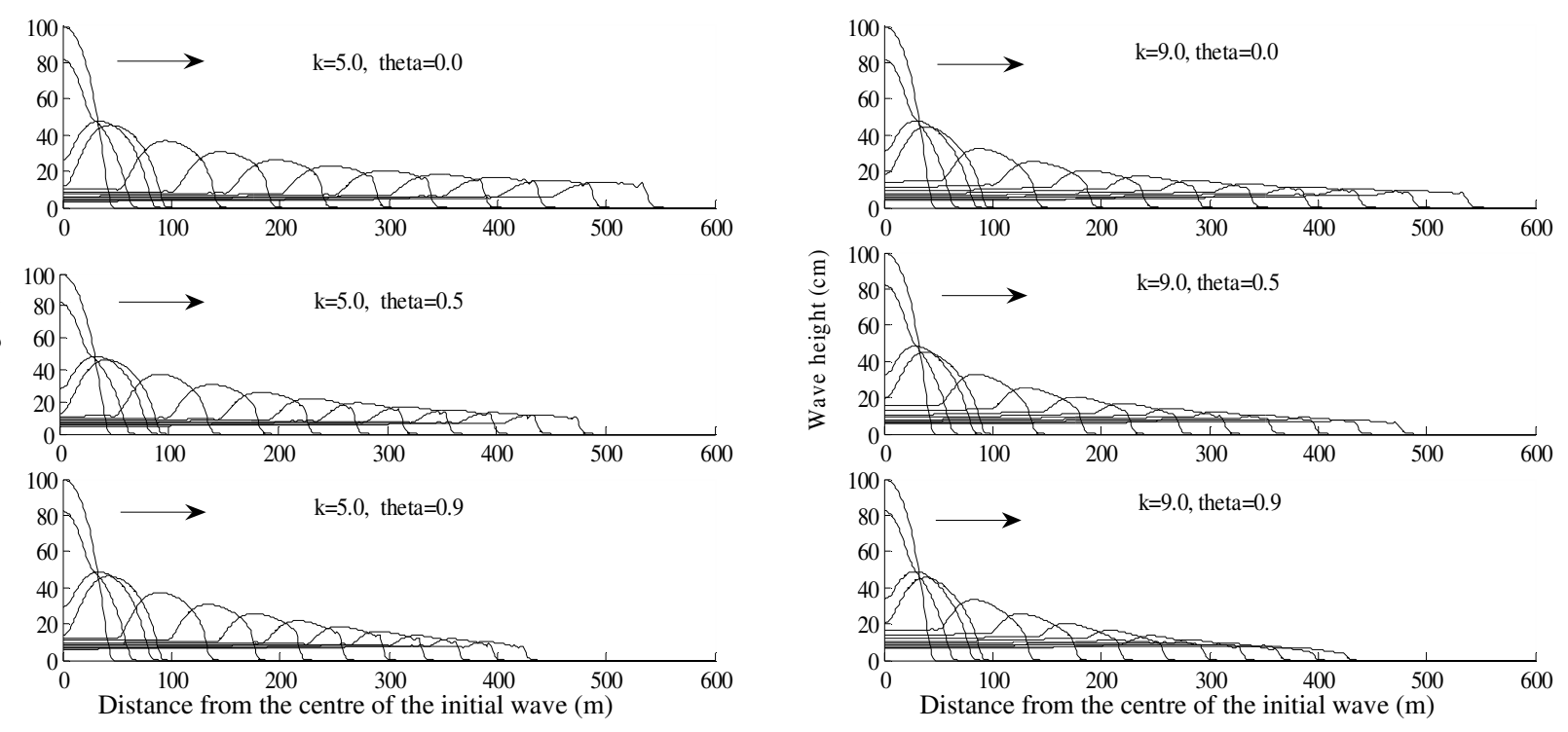

Fig. 5. Numerical results of evolution of long-waves for $k=5.0$ with different $\theta$.

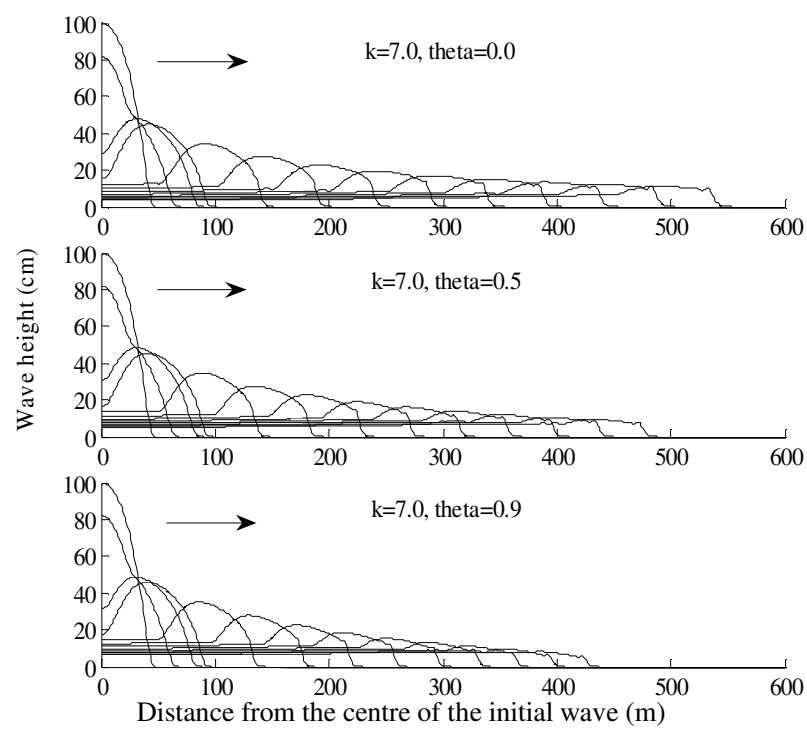

Fig. 6. Numerical results of evolution of long-waves for $k=7.0$ with different $\theta$.

Fig. 7. Numerical results of evolution of long-waves for $k=9.0$ with different $\theta$.

From the results shown in the figures, it can be noted that the disturbed water level becomes lower and lower for small drag coefficients. That is due to the diffusion effect of nonlinear friction on the bottom. For large drag coefficients, the diffusion due to the bottom friction is predominant and the energy kinetic of longwaves is gradually exhausted. Moreover, for small drag coefficients, with the increase in the slope of the bottom, the breaking time decreases.

\section{CONCLUSION}

We have attempted to investigate the effect of nonlinear friction on long wave propagation and breaking. For the case with an even bottom, an analytical solution to the problem has been derived (see [21]), while for the case with sloping bottom, a finite difference method has been developed for solving the problem numerically. The numerical technique has also been used to investigate the propagation of the long waves and the effect of nonlinear friction. The results show higher drag coefficient can pro-long or even can prevent the occurrence of wave breaking. 


\section{ACKNOWLEDGEMENTS}

The author is grateful to Professor Yong Hong Wu of the Curtin University of Technology for his supervision of the research project and his advice and suggestion in the preparation and writing of this paper. The author is also grateful to Professor Efim Pelinovsky of the Institute of Applied Physics, Russia for his invaluable correspondent during the preparation of this paper.

\section{REFERENCES}

1. Carrier, GF \& Greenspan, HP 1957, 'Water waves of finite amplitude on a sloping beach', Journal of Fluid Mechanics, vol. 4, pp. 97-112.

2. Debnath, L 1997, Nonlinear Partial Differential Equations For Scientists and Engineers, Birkhauser, Boston.

3. Fine, IV, Rabinovich, AB, Bornhol, BD, Thomson, RE \& Kulikov, EA 2005, 'The grant banks landslide-generated tsunami of November 18,1929: Preliminary analysis and numerical modelling', Marine Geology, no. 215, pp. 45-57.

4. Guesmia, M, Heinrich, P \& Mariotti, C 1996, 'Finite element modelling of the 1969 Portuguese Tsunami', Phys. Chem. Earth, vol. 21, no. 12, pp. $1-6$.

5. Johnson, HK, Karambas, TV, Avgeris, I, Zauttigh, B, Gonzales-Marco, D \& Caceres, I 2005, 'Modelling of waves and currents around submerged breakwaters', Coastal Engineering, no. 52, pp. 949-969.

6. Kawaraha, M, Kodama, T \& Kinoshita, M 1988, 'Finite Element Method for Tsunami Wave Propagation Analysis Considering the Open Boundary Condition', Comput. Math. Applic, vol. 16, no. 1/2, pp. 139-152.

7. Kim, KY, Reid, RO \& Whitaker, RE 1988, 'On an Open Radiational Boundary Condition for Weakly Dispersive Tsunami Waves', Computational Physics, no. 76, pp. 327-348.

8. Kurkin, A \& Pelinovsky, E 2002, 'Focusing of edge waves above a sloping beach', European Journal of Mechanics, vol. 21, pp. 561-577.

9. Mader, CL 1988, Numerical Modeling of Water Waves, University of California Press, Los Angeles.
10. Okeke, EO 1983, 'On the Linearized Shallow Water waves over the sloping bottom', IL Nuovo Cimento, vol. 6, no. 1, pp. 72-82.

11. Pelinovsky, EN \& Mazova, RK 1992, 'Exact Analytical Solution of Nonlinear Problems of Tsunami Wave Run-up on slopes with Different profiles', Natural Hazards, vol. 6, pp. 227-249.

12. Piatanesi, A, Tinti, S \& Bortolucci, E 1996, 'The wave propagator in the finite element modelling of tsunamis', Phys. Chem. Earth, vol. 21, no. 12, pp. 33-38.

13. Rahman, M 1995, Water Waves: Relating Modern Theory to Advanced Engineering Applications, Oxford University Press Inc., New York.

14. Rogers, SE \& Kwak, D 1991, 'An Upwind differencing scheme for the incompressible NavierStokes equations', Applied Numerical Mathematics, vol. 8, pp. 43-64.

15. Shokin, YI, Khakimsyanov, GS \& Chubarov, LB 1995, 'New Potentialities of Computational Experiment in Tsunami Problem', in RCS D. Leutloff (ed.), Computational Fluid Dynamics, Springer.

16. Smith, GD 1985, Numerical Solution of Partial Differential Equations: Finite Difference Methods, 3 edn, Oxford University Press, New York.

17. Stoker, JJ 1957, Water Waves, Interscience Publishers, Inc., New York.

18. Toda, M 1989, Nonlinear Waves and Solitons, KTK Scientific Publishers, Tokyo.

19. Whitham, GB 1974, Linear and Nonlinear Waves, John Wiley \& Sons, New York.

20. Wu, YH \& Tian, J-W 2000, 'Mathematical analysis of long wave breaking on open channels with bottom friction', Ocean Engineering, pp. 187-201.

21. Zahibo, N, Pelinovsky, E, Talipova, T, Kozelkov, A \& Kurkin, A 2006, 'Analytical and numerical study of nonlinear effect at tsunami modelling', Applied Mathematics and Computation, no. 174, pp. 795-809.

22. Zahibo, N, Pelinovsky, E, Yalciner, AC, Kozelkov, A, Kurkin, A \& Zaitsev, A 2003, 'The 1867 Virgin Island Tsunami', Natural Hazards and Earth System Science, vol. 3, pp. 367-376. 